\title{
Prognosis of pituitary adenomas with arteriographic abnormal vascularization
}

\author{
D. A. ROTH, E. J. FERRIS, ${ }^{1}$ AND U. TOMIYASU ${ }^{2}$ \\ From the Department of Surgery, Harvard Medical School, and Neurosurgical Service, Boston City Hospital, \\ Boston, Mass., U.S.A.
}

SUMMARY A case report and five additional cases from the literature of angiographically demonstrated abnormal vascularization of chromophobe adenomas are presented. The appearance is that of a fine network of vessels appearing in the arterial phase and a homogeneous blush beginning in the capillary phase and lasting throughout the venous phase. The network is derived from dilated branches of the extradural internal carotid artery and is seen in the arterial phase. The stain, appearing in the venous phase, is due to filling of tiny sinusoidal channels and thin-walled vessels throughout the stroma. All the patients had large, actively growing tumours which compressed and infiltrated surrounding structures. Complete tumour removal was not possible in the patients operated upon. The combined morbidity-mortality rate was $83 \%$ and was due to the large tumour size, adherence to vital centres, extreme vascularity during surgical removal, and propensity to bleed spontaneously. The appearance of abnormal vascularity in a pituitary adenoma suggests a poor prognosis.

A brain tumour is diagnosed angiographically by displacement of normally occurring vascular channels and a circulation of abnormal vessels through the tumour. The characteristic angiographic appearance of a pituitary tumour was considered originally to be only that of vascular shift-that is, lateral displacement of the intracavernous internal carotid artery, upward displacement of the supraclinoid internal carotid artery (opening of the siphon), upward and forward displacement of the first portion of the anterior cerebral artery, and upward displacement of the internal cerebral vein (Taveras and Wood, 1964).

More recently, attention has been drawn to the occurrence also of abnormal vascularization in the tumour and tumour capsule (Kricheff and Schotland, 1964; Feiring and Shapiro, 1964; Doron and Schwartz, 1964; Westberg and Ross, 1967). Recent experience with a patient whose angiogram dis-

\footnotetext{
${ }^{1}$ Present address: Department of Radiology, Boston University Medical Center, Boston, Mass.

2Present address: Department of Pathology, Wadsworth V.A. Hospital, Los Angeles, California.
}

Reprint requests to Neurosurgical Service, Boston City Hospital, 818 Harrison Avenue, Boston, Massachusetts 02118, U.S.A. closed abnormal tumour vessels and a review of the other reported clinical cases revealed the potentially serious nature of that specific radiographic finding. This report will describe the angiographic picture and discuss its relationship to the clinical course.

\section{CASE REPORT}

A 53 year old man (H.S.) was admitted to the hospital complaining of recent progressive loss of vision. He had first noted visual difficulty 10 years earlier. On the basis of a bitemporal hemianopsia and a radiographically enlarged sella a diagnosis of pituitary tumour was made, and he received a course of orthovoltage $x$-ray therapy. He recovered a significant amount of peripheral vision and was able to return to his employment as a social worker.

After a second episode of visual deterioration one year before admission, he underwent a course of $\mathrm{Co}^{60}$ therapy with only a mild transient improvement. He was troubled as well by increasing lassitude and easy fatiguability which prevented him from working.

On physical examination the patient was mildly obese and lethargic. He had a visual acuity of $20 / 100$ bilaterally, a dense bitemporal hemianopsia with macular sparing, and pale optic discs. Radiographs of the skull revealed a moderately enlarged sella turcica with thinning of the floor and posterior clinoid processes (Fig. 1). 


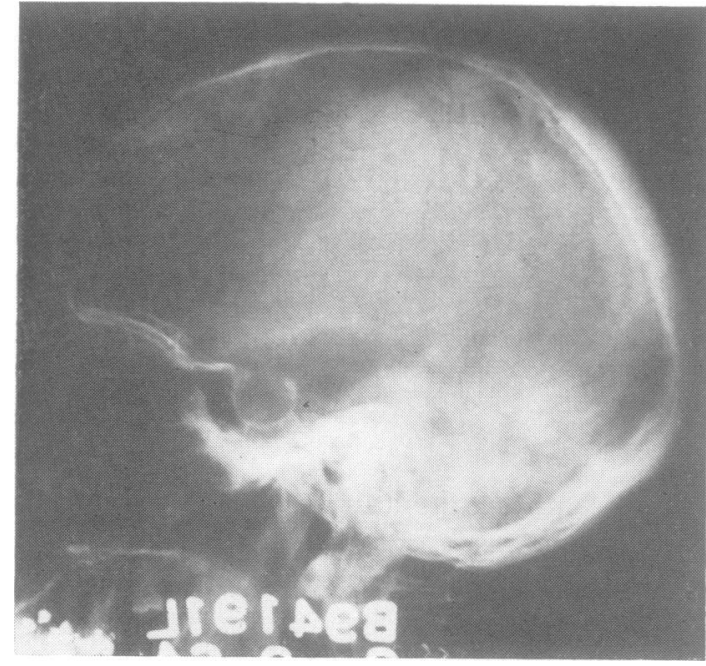

FIG. 1. Sella is enlarged with the floor thin and the posterior clinoid processes eroded.

A left carotid arteriogram demonstrated lateral displacement of the cavernous portion of the internal carotid artery, an uncoiling of the supraclinoid portion of the internal carotid artery, and elevation of the horizontal portion of the anterior cerebral artery (Fig. 2a, 2b). In

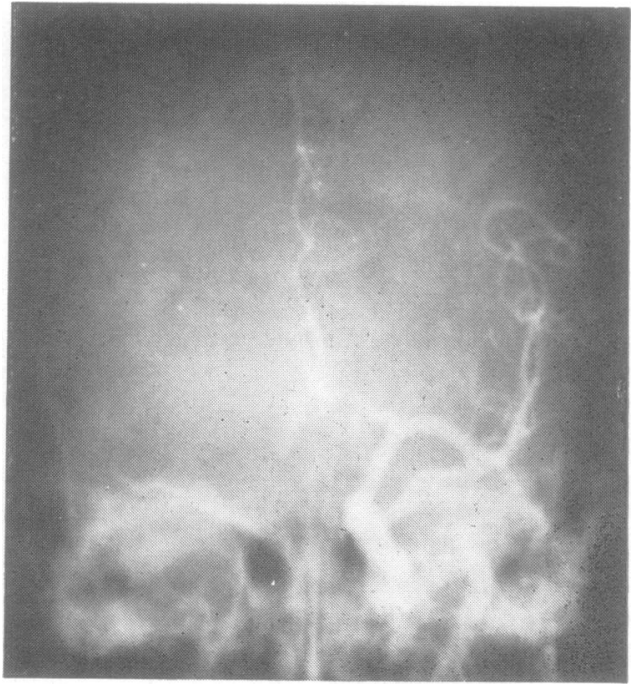

FIG. 2a. The internal carotid artery is displaced laterally and the anterior cerebral artery is elevated.

addition, there were numerous, delicate vessels which $\frac{\text { Oे }}{\overrightarrow{0}}$ outlined a mass above and behind the sella (Fig. 3). They $\frac{\rho}{9}$ 을 appeared to be hypertrophied branches originating from $\propto-$ the superior hypophyseal and inferior meningohypo- 0 physeal arterial trunks. The network of vessels defined a 8 के

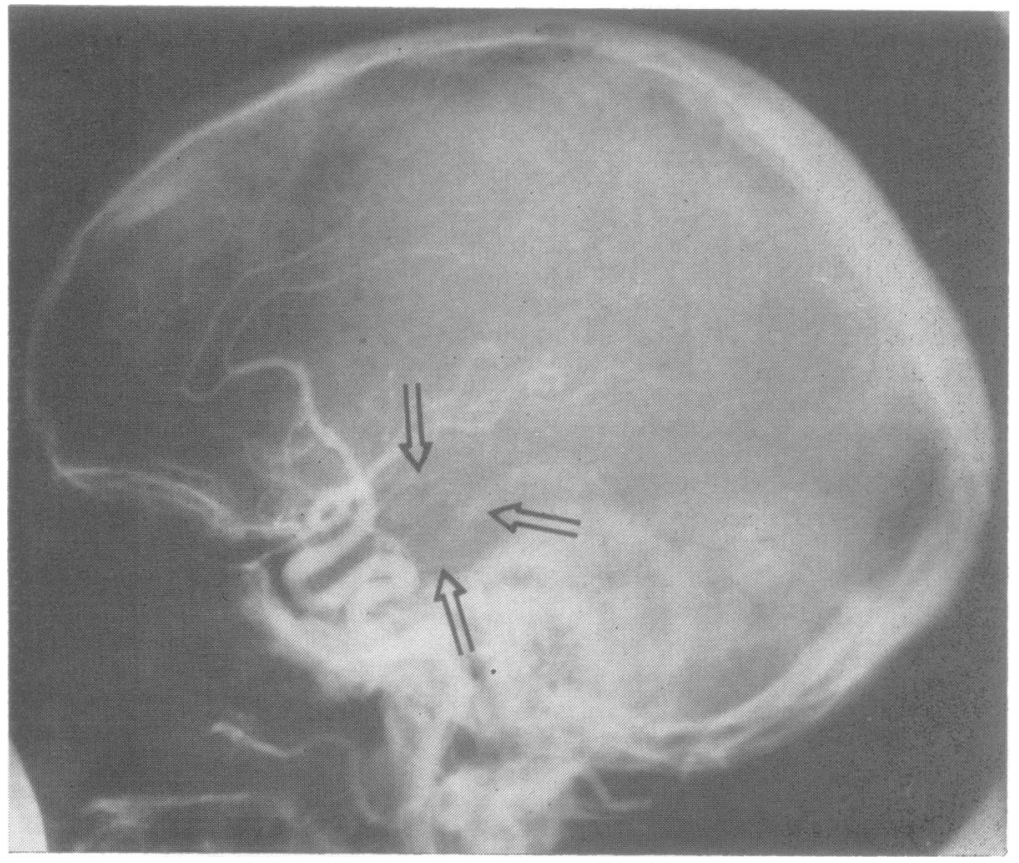

FIG. 2b. The siphon of the internal artery is uncoiled. A tumour stain is present above and behind the sella. 


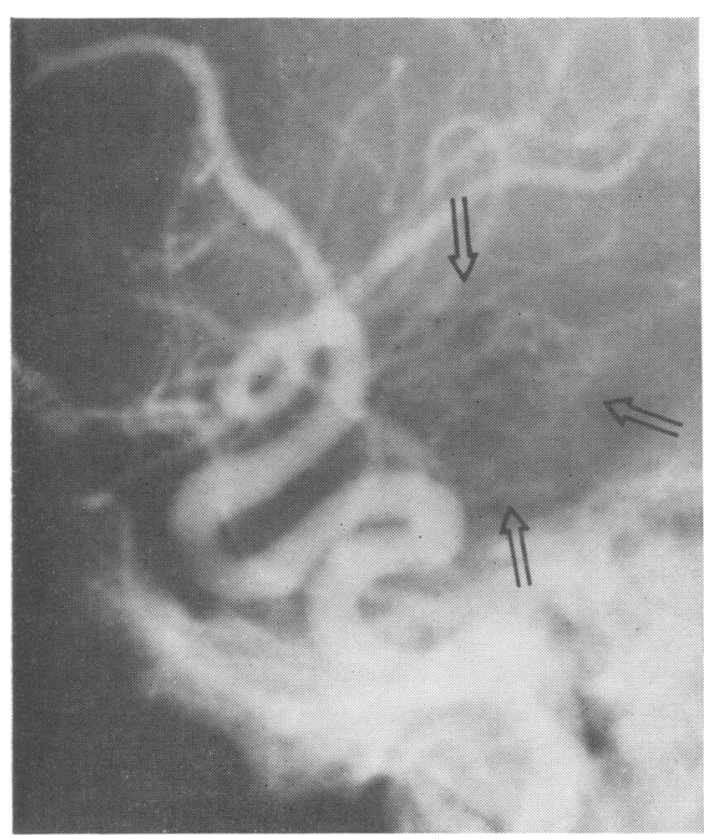

FIG. 3. Arterial tumour stain.

well-circumscribed and somewhat lobulated capsule. The later films revealed an elevation of the anterior portion of the internal cerebral vein. A more striking finding in the venous phase was a vascular blush which was present in the suprasellar area (Fig. 4). Anteriorly it was a dense, fairly homogeneous cloud drained by several large veins. Posteriorly it was less dense but outlined the same mass seen in the arterial phase.

The patient became increasingly obtunded, restless, and unable to leave his bed. Because of lack of response to radiotherapy and clinical deterioration he was taken to the operating room for surgical removal of the tumour. However, he became severely hypotensive under general anaesthesia in spite of preoperative adrenal corticosteroid coverage and the operation was postponed. He became more obtunded and several days later, after experiencing the acute onset of severe headache, lapsed into coma. He quickly developed signs of brain-stem dysfunction and died.

Post mortem examination revealed gross intraventricular haemorrhage extending into the basal subarachnoid cisterns. A large friable mass arising as a dumbbell from the pituitary fossa lay above the sella, filling the interpeduncular fossa, compressing the thalamus and midbrain. On sagittal section the haemorrhagic tumour had eroded into and filled the third ventricle (Fig. 5).

Microscopically, the neoplastic cells were distributed diffusely throughout the tissue (Fig. 6a). They were small and round with distinctly chromated nuclei. The scant cytoplasm did not contain any granules visible with special staining techniques. Thin-walled vessels were present in large numbers and many had been overgrown by collagenous tissue with obliteration of the lumens and loss of vascular architecture (Fig. 6b). A portion of the tumour had begun to invade the lateral wall of the third ventricle.

\section{DISCUSSION}

Angiography has been used primarily to confirm the

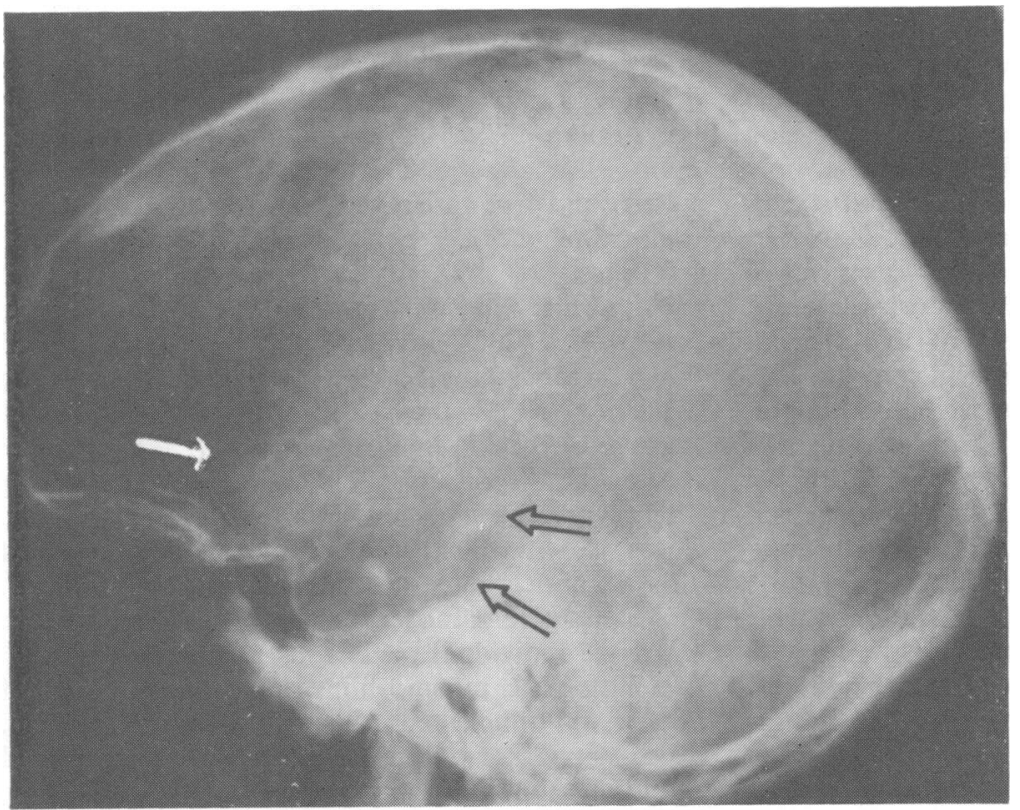

FIG. 4. Venous phase shows a poorly defined homogeneous blush in the same area. Superior border cannot be definitely outlined. Compare with outline of tumour in Fig. 5. 


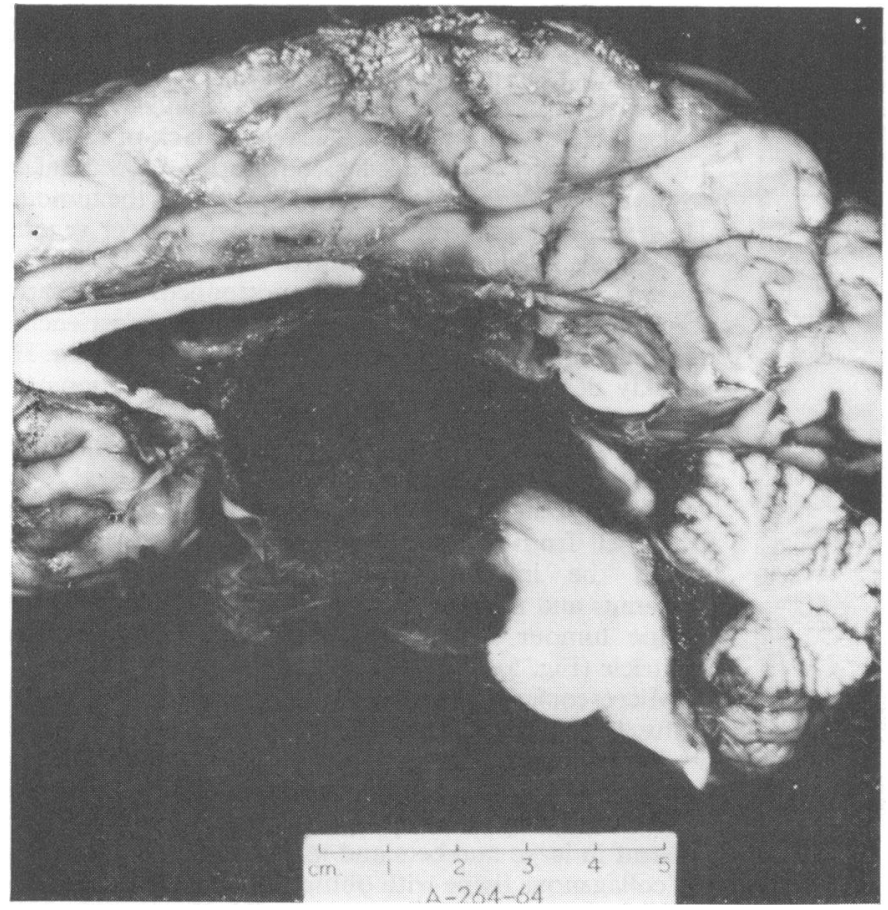

FIG. 5. Sagittal section of the brain. The haemorrhagic, necrotic tumour fills the interpeduncular fossa and third ventricle. Blood clot occludes the fourth ventricle.

diagnosis of suprasellar tumour obtained by pneumoencephalography and to exclude the possibility of an arterial aneurysm. Attention was directed originally at displacement of vessels in the vicinity of the sella. Recent reports (Taveras and Wood, 1964; Kricheff and Schotland, 1964; Feiring and Schapiro, 1964; Doron and Schwartz, 1965; Westberg and Ross, 1967) have also noted the occasional appearance of abnormal vascularization within the tumour and its capsules. Altogether only 12 cases have been well documented, so that it cannot be considered a frequent occurrence. However, Doron and Schwartz (1965) found four cases out of 23 studied and suggested that, with increasing use of serial angiography and awareness of this type of tumour as a possible manifestation, it may be seen more often in the future than was originally thought.

The abnormal vascularity appears as two distinct systems. Hypertrophied branches arising from the extradural portion of the carotid siphon which appear as a well-defined network are seen quite early in the arterial phase. Westberg and Ross (1967) noted that the presence of the arterial channels correlated well with hypervascularity of the tumour capsule at surgery and concluded that the vessels were capsular rather than parenchymal. The homogeneous tumour blush which begins to appear in the capillary phase and lasts throughout the venous phase probably represents diffuse small vessel filling in the parenchyma, the same ubiquitous sinusoidal channels seen microscopically.

The clinical features of five reported cases together with the one reported here are sufficiently documented to make comparison possible. There are certain similarities in the clinical manifestations of the cases. The first is the extreme vascularity of the tumours. Two of the four tumours operated upon were described as abnormally vascular at surgery and produced severe bleeding upon attempted removal. Two other tumours bled spontaneously.

The second similarity is the extensive nature of the tumours. They were exceedingly large and active, compressing and invading surrounding cerebral tissue, blood vessels, and bone, and producing hypertrophy of their supplying blood vessels. Because of their intimate adherence to adjacent vital centres they could only be removed incompletely.

The tumours were difficult to treat successfully. Three patients died after operation. Another died after a spontaneous haemorrhage into the tumour. One patient remained neurologically incapacitated. Only one individual made a useful recovery.

Histological pleomorphism, hyperchromasia of nuclei, multinucleated cells, scant cell cytoplasm, dense networks of capillaries, mitotic figures, and actual invasion of brain tissue separately or together, 


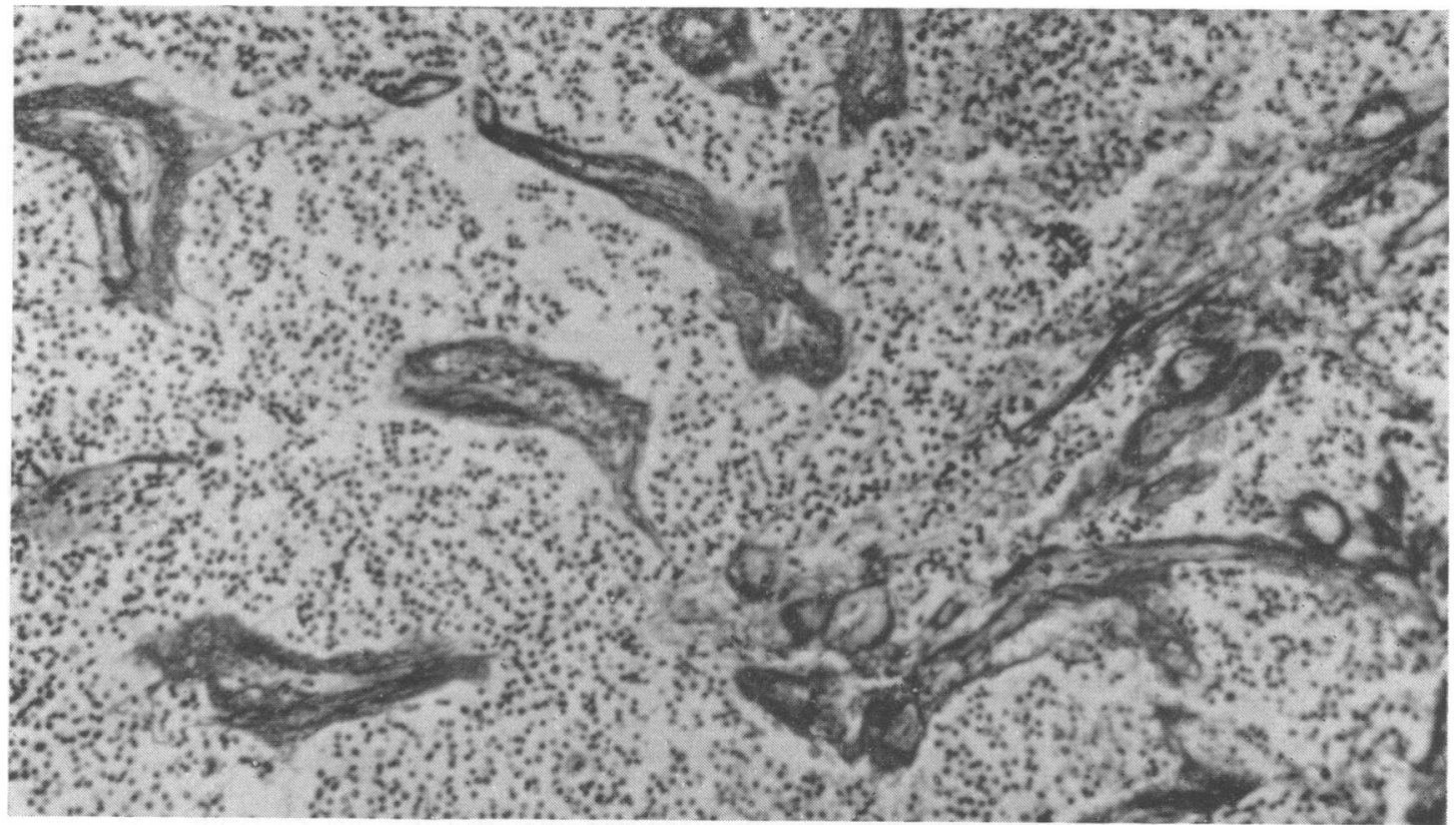

FIG. 6a. Section from tumour. Small, densely chromated cells are spread diffusely throughout. Many thin-walled blood vessels are present.

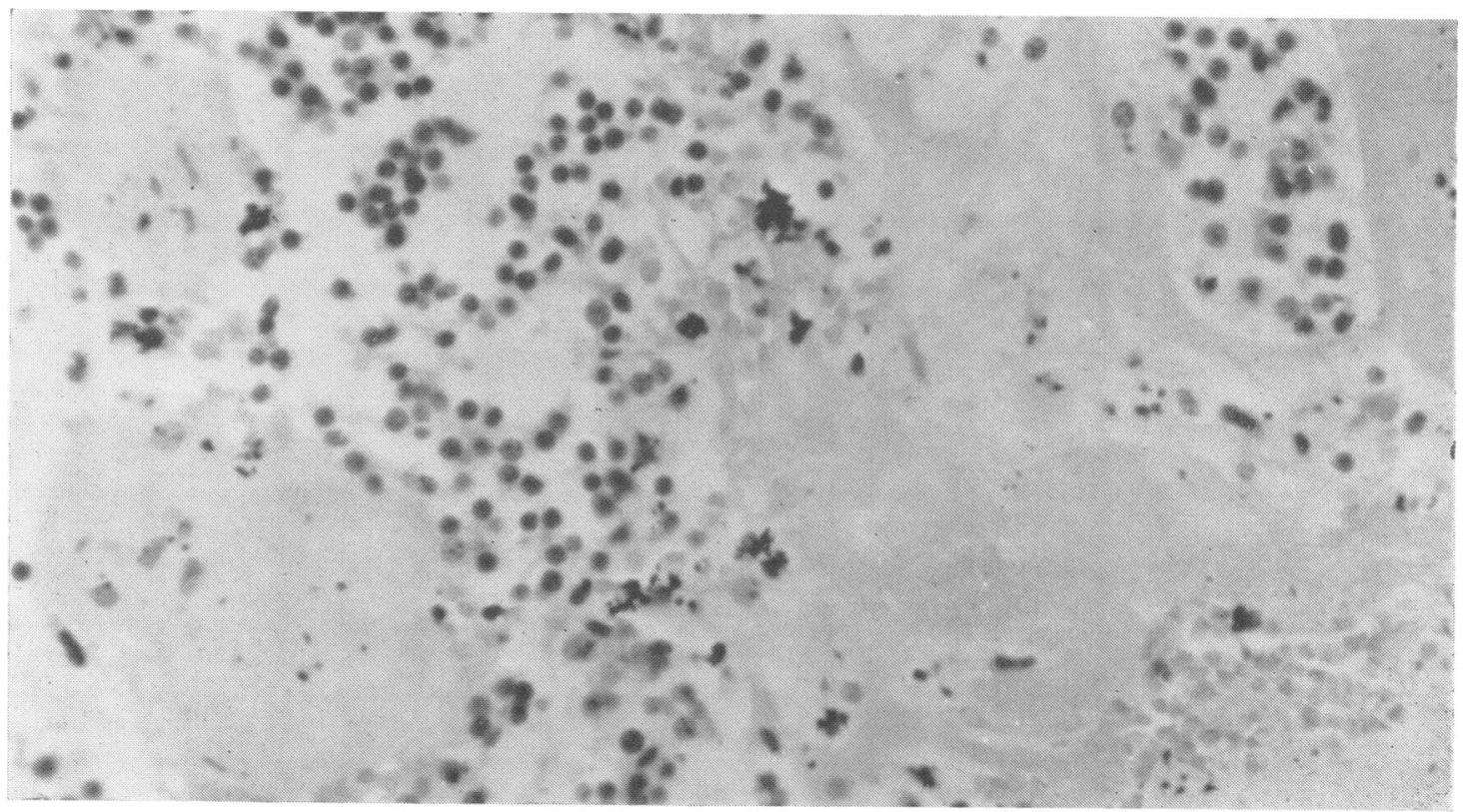

FIG. 6 b. Blood vessels are replaced by collagenous tissue. 
were seen in all six cases. Although the microscopic characteristics of malignancy in pituitary adenomas have not been unequivocally defined, the rapid growth, extremely large size, vascularity, tendency towards necrosis and spontaneous haemorrhage, and the compression and invasion of surrounding structures made these tumours clinically if not histologically malignant.

A combined mortality-morbidity rate of $80 \%$ is considerably higher than in published series of chromophobe adenomas. Cushing had only a $2 \%$ mortality in the cases operated upon in the last 10 years of his study (Henderson, 1938). Jefferson reported a $2 \%$ mortality in patients with average size neoplasms (Jefferson, 1940), and Olivecrona's series yielded a $6.4 \%$ mortality rate for the same group (Bakay, 1950).

It is well known that larger tumours are more lethal. Surgical removal of neoplasms with large extrasellar extension carry mortality rates of 33 to $35 \%$ (Jefferson, 1940; Bakay, 1950). However, the death rate in patients with angiographically visualized abnormal circulations of $83 \%$ suggests that their increased metabolic activity and vascularity make them almost completely resistant to present modes of therapy.

The role of radiotherapy in producing an angiographic tumour stain is unknown. It has been linked in the literature with pituitary apoplexy and both of the patients reported here with haemorrhage into the tumour had received radiotherapy. However, half of the patients had not had any radiotherapy. In addition, the effects of radiotherapy are usually those of endothelial swelling and vascular occlusion rather than vascular proliferation (Warren, 1942). More likely, the large size and rapid tumour growth necessitated an increase in the vasculature to supply and keep pace with the neoplasm.

\section{REFERENCES}

Bakay, L. (1950). The results of 300 pituitary adenoma operations (Professor Herbert Olivecrona's series). J. Neurosurg., 7, 240-255.

Doron, Y., and Schwartz, A. (1965). The significance of the angiographic demonstration of tumour vessels in pituitary neoplasms. Brit. J. Radiol., 38, 356-359.

Feiring, E. H., and Shapiro, J. H. (1964). Evaluation of angiography in the diagnosis of suprasellar tumors. Amer. J. Roentgenol., 92, 811-828.

Henderson, W. R. (1938). The pituitary adenomata. A followup study of the surgical results in 338 cases (Dr. Harvey Cushing's series). Brit. J. Surg., 26, 811-921.

Jefferson, G. (1940). Extrasellar extensions of pituitary adenomas. Proc. roy. Soc. Med., 33, 433-458.

Kricheff, I. I., and Schotland, D. I. (1964). Tumor stain in a pituitary adenoma. Radiology, 82, 11-13.

Taveras, J. M., and Wood, E. H. (1964). In Diagnostic Neuroradiology, pp. 643-655. Williams and Wilkins: Baltimore.

Warren, S. (1942). Effects of radiation on normal tissues. VI. Effects of radiation on the cardiovascular system. Arch. Path., 34, 1070-1084.

Westberg, G., and Ross, R. J. (1967). The vascular supply of chromophobe adenomas. Acta radiol. Diagn., 6, 475-480. 